\title{
THE RESPIRATOR AND THE MECHANISATION OF NORMAL BREATHING
}

\section{Breath prosthetics}

In 1937, a physician led nine patients down to the basement of the Brompton hospital and into a compressed air chamber called an 'air bath'. It must have been an eerie experience. Air baths had fallen out of fashion years before, and were situated in the basement of the hospital, near the engine room and adjacent to three Turkish baths. Even when such machines had been in regular use in the nineteenth century, historian Jen Wallis notes that the Brompton ones were remarkably 'medicalised and industrialised' and, once inside, the patient was entirely isolated and disconnected from the outside world. ${ }^{1}$ The two air baths at the Brompton hospital were purchased between 1879 and 1880 and were originally designed to prevent the advancement of consumption for patients in the early stages of the disease. ${ }^{2}$ Since their usage had fallen into disrepute in the intervening fifty-seven years, it must have felt very strange for the patients to be led into these dark, unfamiliar and no doubt dusty old machines. ${ }^{3}$ However, the consulting physician, George Ernest Beaumont (1888-1974), had a theory that the compressed air baths could work to bring into use previously dormant alveoli' by opening them up through the 'pressure of oxygen in the atmospheric air." Before undergoing this experimental treatment, the nine chosen patients had their vital capacity measured by Beaumont, and this was done again upon their exit from the machine. Beaumont explained that, 'the VC readings did not improve so did not support the idea that they opened up the alveoli. ${ }^{5}$ For Beaumont, this confirmed the limited value of the treatment. The patients, however, did find value in the experience. Beaumont noted that 'Eight patients stated that while in the bath they experienced sensations described as "comfort" "looseness" or "freedom". Two patients considered that they were constantly less short of breath than they had been before the 
treatment was started. ${ }^{6}$ However, because their spirometric readings did not indicate improvement, the patients' assessment of the value of the air bath was entirely disregarded. Their testimony was noted - but downgraded against the superior numerical data provided by the spirometer. This vignette provides another example of mechanical epistemic injustice and highlights the tension inherent to assessing individual experience of technologies designed to assist breathing.

The previous chapter highlighted the difficulties of classifying individual respiratory disability. In this chapter I explore how those so classified lived with this disability in the interwar period. To do so, I examine the ways in which various institutional and individual bodies engaged with technologies to extend, adapt and supplement their breath. As the last chapter emphasised, the invisibility and individuality of normal breathing made it a particularly difficult phenomenon to measure as standard. These difficulties similarly permeated attempts to design assistive respiratory technologies.

The possibility of using technology to facilitate breathing was advanced during the early twentieth century partly because of the prevalence of seasonal polio epidemics which could leave victims with paralysed respiratory muscles. However, as in the case of the hearing-assistive technologies discussed in Chapter 4, there were debates during the interwar period about which bodies ought to be responsible for providing and perfecting such technologies. Should respiratory technologies be designed by engineers or by medical men? Or by those using the technologies themselves? In this debate, there were parallels between the development of assistive technologies designed for hearing loss and breathlessness. By utilising such assistive technology, the user makes visible a previously invisible disability, and in doing so, can become subject to increased stigmatisation. ${ }^{7}$ Both technologies are also notable for high levels of user innovation and, as I explain in the section below on the origins of pneumatic medicine, individual experimentation was incorporated into its beginnings. User modification of respiratory technologies is explored further in the section that follows, which analyses an early 'breathing machine' called the Bragg-Paul pulsator, originally designed in collaboration between a user and an engineer. ${ }^{8}$ Yet the embodied knowledge that was used to create this mechanical respirator was not accepted by the medical establishment. Physiotherapists disputed its viability and questioned the health benefits of the principles by which the pulsator operated, and we will see in the section on 'Patient experiences in the machine' that this dispute led to the MRC leading an intervention to decide on a 'standard' breathing machine. However, these inimitable breathing machines proved to be remarkably difficult to standardise. 
Technologies designed to enable breathing are unique in their association with life, death and voice. ${ }^{9}$ As I have previously discussed with philosopher Havi Carel and healthcare professional Kate Binnie, 'technologies bringing oxygen into the body have a special symbolic resonance related to fundamental meanings associated with breath (e.g. life, spirit, inspiration). These meanings and the experience of their antonyms (death, struggle, expiration) contribute to a gripping and pervasive anxiety that cannot necessarily be ameliorated by technology alone. ${ }^{10}$ Here I recover historical experiences with respiratory technologies by prioritising users' voices. In doing so, I outline (in the section 'From home to hospital') the extent to which user experiences and voices were prioritised or not as respiratory technology moved from the home to the hospital during the interwar period. The lack of recognition of the individuality of breathing meant these individuals were inspired to adapt and 'tinker' with respiratory assistive technology in order to make them work for them. It is important to note, however, that certain of the respiratory technologies in this chapter were designed to manually stimulate the lungs, facilitating the breath by literally forcing compression of the chest. This kind of respiratory-assistive technology does the breathing for the user (like a modern-day ventilator) and thus differs from the kind of ambulatory oxygen which gives auxiliary oxygen to its user, which we might now more commonly associate with the term 'breath prosthetic'. However, using oxygen in this way does have important historical precedent in the field of pneumatic medicine, which I explore in the next section to set up the connections between measurement, individuality and oxygen, a theme I return to in the conclusion to this chapter.

\section{The origins of pneumatic medicine}

The radical individualism that characterised Enlightenment thinking was central to the eighteenth-century race to identify oxygen as a discrete substance distinct from the surrounding air. ${ }^{11}$ In the process of his experiments with mice trapped in bell jars Joseph Priestley (1733-1804) initially termed the unknown air he had isolated 'dephlogisticated air' in line with the then dominant understanding of combustion as resulting from phlogiston. This was, of course, replaced by the 'fragile' oxygen theory 'crafted by Lavoisier', as Hasok Chang has put it. ${ }^{12}$ But before the so-called 'chemical revolution' Priestley had generated 'oxygen' by placing powdered mercuric oxide (previously burnt mercury) in a bell jar so that the gas it generated would be captured in a bottle above. ${ }^{13}$ When he put a candle in the bottle containing the gas, the flame burnt more strongly. Priestley therefore surmised that this was a 'new' kind of pure air, which could be important for processes including combustion, 
calcination and respiration. ${ }^{14} \mathrm{He}$ experimented with mice, showing that they could live and prosper in this newly isolated gas, whereas they would die rapidly in a sealed container filled with 'common air. ${ }^{15}$ Following the mice trials he immediately experimented on himself, and after he inhaled the unidentified air, mused: 'I fancied that my breath felt peculiarly light and easy for some time afterwar. Who can tell but that in time this pure air may become a fashionable article in luxury.16

Such emphasis on the individual sensory experience of breathing marked initial experiments with oxygen as a health substance. David Phillip Miller and Trevor H. Levere have argued that the initial development of pneumatic medicine can be encapsulated in the phrase 'inhale it and see. ${ }^{17}$ Individual experience was crucial to the pneumatic medicine project, and sensory experience was integral to the production of knowledge about breathing. Thus, we can see that the individual body has at various points played an important part in developing knowledge about respiration technologies.

There was great initial optimism about using such 'airs' to treat disease, evident from the creation of institutions like the Pneumatic Institution, founded by Thomas Beddoes (1760-1808) in Hotwells, Bristol, in 1799..$^{18}$ Beddoes was assisted by Humphrey Davy (1778-1829) and was joined by James Watt (1736-1819) in 1794. Their collaborations between 1792 and 1798 focused on devising apparatus that could deliver various airs to patients. ${ }^{19}$ The typical treatment at the institution was 'a pint of oxygen air in a bagful of common air. ${ }^{20}$ This bagful of air was literally a bag full of air. Usually the bag was made of oiled silk material and the air would ideally be inhaled directly from the bag into the mouth. ${ }^{21}$ Mouthpieces were developed for users who found this difficult, initially comprised of two valves of silk and a small pipe. Eventually, mouthpieces were created from materials including vulcanite, glass, metal, ivory, velveteen and leather. ${ }^{22}$

Beddoes and Watt's ideas about the medical uses of airs were published in Considerations on the Medicinal Use and Production of Factitious Airs in $1795 .{ }^{23}$ Included in this book were reports from individual users experimenting with oxygen as well as case notes from physicians using oxygen on their patients. Beddoes made notes under each of the cases, which are rich in idiosyncratic personal details. Take the 1795 case of Mr Danby, who relates that he got drunk on port wine at an inn near Lymington before he fell into sickness which threatened his life for five months until he was able to 'make trial of the vital air'. Upon acquiring some from a Dr Thornton, he reported that 'A week has not passed from the time of my first inhaling the vital air, before my appetite returned, and my nights were rendered so comfortable and refreshing that my wife could scarce get me up at a reasonable hour in the morning. ${ }^{24}$ 
The movement of oxygen therapy machines from chemistry to medicine during this period mirrored the uptake of electric therapy. In both cases, there was initial optimism and a sense of harnessing the power of nature to heal, as well as conflict around how to quantify sensorial knowledge. ${ }^{25}$ Historian Vanessa Heggie has argued that there have been long historical tensions around bodily knowledge versus laboratory knowledge in the design of artificial respiration. For example, she has shown that by the middle of the twentieth century, physiological 'facts' related to technologies of artificial respiration used in mountaineering could not be created in laboratories and were only accepted if they had been established through field observations made by individuals on the mountain. ${ }^{26}$

Medicinal use of oxygen fell out of favour in mainstream medicine during the 1800s and was largely abandoned before becoming specialised and reinstitutionalised within hospital medicine. ${ }^{27}$ Oxygen use was revived during the First World War, when portable oxygen was used to treat the victims of poison gas in $1917 .{ }^{28}$ The work of John Scott Haldane helped to demonstrate and standardise the use of oxygen therapy for those affected by poison gas, but opinions differed concerning its efficacy in the treatment of respiratory disease, and there were concerns over whether it should be given continuously or intermittently. The Haldane Oxygen Administration Apparatus was developed for treating poison gas victims, and this took the form of a metal gas mask. It was then brought into use in general medicine and described in 1921 as the most 'efficient, convenient, and economical method for oxygen administration', but a drawback to its usage was the fact that the mask could be 'strongly resented' by patients and was not tolerated in some cases. ${ }^{29}$ In the post-war period, one can imagine that the use of an apparatus which so closely resembled a gas mask may have caused particular discomfort and disorientation, especially in children. If the mask was rejected, the nasal catheter method (which involved inserting the tube directly into the nose) could be used, but this was often criticised for its inefficiency. In an emergency, Dr Whitridge Davies recommended in 1922 that a cardboard hat box could be appropriated. ${ }^{30}$

Between 1920 and 1940 there were disputes about whether oxygen should be given at all, and if so, for what conditions, under what circumstances and in what form? In 1921, for example, William C. Stadie (1886-1959) described an oxygen chamber used for pneumonia treatment at the hospital of the Rockefeller Institute for Medical Research. This oxygen chamber was built just off the main ward and included a 'food lock' for passing food and small items without opening the door. The patients enclosed within could communicate with the outside world by telephone. ${ }^{31}$ This was the method of oxygen 
administration carried out in the Cambridge Physiological Laboratory to treat men gassed in the First World War. ${ }^{32}$

However, the more traditional means of administrating oxygen at that time was still by 'means of a rubber tube and glass funnel'. ${ }^{33}$ This funnel was described in 1924 by Dr G. D. Laing as commonly used but expensive and ineffective. ${ }^{34}$ Laing also felt that the various masks available were not appropriate for nervous patients or children, describing them as 'cumbersome, uncomfortable, and distressing to the patient. ${ }^{35}$ He advocated instead for the catheter to go into the mouth. It could then be fixed to the cheek or chin by a plaster, or for children the tube could be dipped into sugar and water flavoured with peppermint. ${ }^{36}$ His criticism appeared in the context of a debate in the British Medical Journal in 1924 about the best way to administer oxygen. The funnel-style methods were criticised in the Edinburgh Medical Journal in 1922 by Dr Whittington Davies as faulty and ineffective and were blamed for oxygen's usage falling into disrepute. ${ }^{37}$ Like Laing, Davies argued that it was a mistake to administer oxygen only as a last resort before death, and that it should instead be considered as type of drug treatment which should be given early, ideally through encasement in an oxygen chamber. The other alternative Laing considered better than mask administration was the oxygen tent. Measurement of oxygen level in the individual body was not yet feasible and administration of oxygen at a level above 40-60 per cent was considered dangerous because it had been shown to cause fatal pneumonia when trialled on animals. ${ }^{38}$

However, technologies designed by individuals for individuals could succeed in a way that confounded the expectations of the medical establishment. This is especially evident in analysis of the Bragg-Paul pulsator, which was originally invented by Nobel prize-winning physicist William H. Bragg (18621942) in collaboration with its user, his neighbour Samuel Crosby Halahan (1869-1936). ${ }^{39}$

\section{The Bragg-Paul pulsator}

Captain Samuel Crosby Halahan lived in West Sussex and had what Bragg described as a 'terrible wasting of the muscles. ${ }^{40}$ Not much is known about Halahan's life other than he served in the military and that his friendship with Bragg resulted in the design of a new home-made 'breathing machine'. Beginning in 1926, Halahan began progressively losing all 'power of moving his limbs' until he was unable to drive a car or write, and he gradually lost weight. Halahan was unable to breathe without assistance for over a year, eventually employing two nurses: 
For a long time two nurses were employed giving artificial respiration continually: the wife felt very much the disability of being unable to speak to him except in the presence of a nurse because her strength had considerably diminished due to the strain of her husband's illness, and she was unable therefore to give artificial respiration herself. ${ }^{41}$

Halahan's respiratory paralysis, which first began in 1931, was diagnosed as resulting from progressive muscular atrophy; continuous artificial respiration was necessary to keep him alive from the onset of paralysis until his death in 1936 at the age of sixty-six. ${ }^{42}$ Given the strain continuous artificial respiration placed on Halahan's relationship with his wife, Bragg 'had the idea that [he] could ease matters by a simple system of india [sic] rubber bladders, football bladders in fact' to substitute the human effort. To devise this automated system, he bandaged one of the bladders under a binder on Halahan's chest and the other to a pair of hinged boards on the ground, then connected the two with a long tube. This bellows device applied rhythmic pressure directly to the chest, forcing the diaphragm to contract and air to enter and leave the lungs. Bragg's invention used positive pressure (unlike the iron lung, which used negative pressure) to enforce expiration of air by forcing the ribs in.

Despite the mechanical improvement, the labour remained arduous for the nurses and Maud (his wife), so Bragg asked instrument maker Robert W. Paul (1869-1943) to construct a small hydraulic machine which could be connected to the main water supply. ${ }^{43}$ This new design worked effectively except on occasions when the water pipes froze or the water supply was shut off for repairs without notice - and was estimated to have caused 15 million involuntary respirations in Halahan's lifetime. ${ }^{44}$ It was discreet, as the hollow bandage that replaced the football bladder could be hidden by the bedcovers. ${ }^{45}$ Furthermore, it made Halahan's relationships easier, as Maud could 'give artificial respiration while she sits and reads to her husband' and only one nurse was required to assist. ${ }^{46} \mathrm{He}$ wore the device for up to seventeen hours at a time, as he could not 'bear the constriction of the bandage' all day; the remaining hours were filled with manual respiration. ${ }^{47}$ Bragg's portable system offered Halahan more mobility, privacy and control over his own breathing. The system was adjusted to fit to Halahan's body, leaving him 'free to do as much as he could have done if it had not been applied. ${ }^{48}$ It was even allegedly modified so that it could be used while driving. ${ }^{49}$

As I have previously argued alongside Carel, the elements of co-production in its design origins involved engagement with the patient's needs beyond the strictly medical. ${ }^{50}$ For example, it was inconspicuous and could be easily disguised so 'that there was no evidence of anything unusual except the quiet click-clack of the pulsator in another part of the room. ${ }^{51}$ The pulsator method 
was a relatively cheap and portable respirator which offered its users a relatively high degree of mobility and independence. Such considerations were set up in comparison to the so called 'iron-lung'-style respirators which developed concurrently with the pulsator. The first 'iron lungs' were designed in the USA at Harvard University by Philip Drinker (1894-1972) and Louis Agassiz Shaw, Jr (1886-1940), and used (negative) vacuum pressure to mechanically force a patient's diaphragm to expand and contract to exert alternating pressure through a push-pull motion. ${ }^{52}$ By regulating the rate and depth of respiration, the device allowed for prolonged artificial respiration, either until the patient recovered muscle strength or until an alternative method of treatment became available.

The Drinker device, as it became known, was first used in the UK in $1930 .{ }^{53}$ However, it was expensive, bulky and heavy, and so difficult to transport. It was eventually superseded by Australian inventor Edward T. Both's (1908-87) plywood-based iron lung, which was presented as a more affordable alternative. ${ }^{54}$ Like the Drinker device, the Both iron lung required the patient to be entirely encased in a cabinet with only the head protruding and with only the capacity to eat, drink and sleep. ${ }^{55}$ However, the depth and rate of their breathing was controlled by an attendant, not by the patient. ${ }^{56}$ One user described the challenge of moderating eating and breathing patterns to the machine:

You can eat in the iron lung because your head is outside but the rest of your body is inside, although since you are flat on your back you really need to be careful when you swallow; you have to swallow in rhythm with the machine because it's pulling your diaphragm in and then pushing it out again. You just wait until it's breathing out and then you swallow. Coughing was a bit more difficult because you don't cough in rhythm with the iron lung. It was something you had to work around. ${ }^{57}$

By comparison, through using positive pressure to force expiration of air, the Bragg-Paul pulsator represented a cheap and portable alternative to the ironlung respirators, designed such that it could be carried by a single porter for use in a private home or a hospital ward. ${ }^{58}$ Bragg's initial iteration worked through manual rhythmical manipulation of the pump, and Paul ensured that the bellows could be actuated by hand as well if necessary. Yet, even though their design provided greater agency to the patient by freeing them from completely mechanised enclosure, the breathing was still controlled by an attendant. This reliance and the need to protect the pulsator against any unforeseen complications (such as electrical or water failures) meant that Halahan was never left alone. He was also to use his tongue and teeth without breath to sound an alarm danger signal 'resembling that of a bird' to alert the attendant. ${ }^{59}$ This 
technique is similar to 'frog breathing', which involved patients with paralysed chests utilising the muscles of the neck to breathe in a gulping fashion 'like a frog. ${ }^{60}$

The benefits of a portable, semi-mechanical respirator being widely available were not lost on Bragg and Paul. In 1933, Bragg contacted several hospitals to inquire whether there was any medical interest in the pulsator. One reply, from K. N. Knapp of Swindon and North Wilts Victoria Hospital, agreed that it would be beneficial to have the device in the hospital, arguing that such 'a semi-mechanical respirator would often be most useful, and would save labour and Staff'. ${ }^{61}$ Knapp also advised Bragg to contact physiologists to improve the mechanisation of the device and so Paul contacted Dr Edward Poulton at the London School of Hygiene and Tropical Medicine, to help work out how to standardise the measurements of ventilation efficiency needed for different patients. ${ }^{62}$ This was a necessary step for allowing large-scale usage of the respirator and for its incorporation into a hospital setting. ${ }^{63}$

To ensure the pulsator was available to hospitals, and to popularise it as an alternative to iron lungs, Paul took upon himself the financial responsibility to order six devices for hospitals using his limited personal funds. Both Bragg and Paul explained that they were not 'financially interested' in their machine and thus chose not to patent it or request royalties. ${ }^{64}$ The machine was manufactured by the firm Siebe Gorman and Co. (who had made the aforementioned Haldane gas masks) at a cost of $£ 30 .{ }^{65}$ They also substituted steel for brass in certain parts to 'strengthen the design of the apparatus. ${ }^{66}$ By this stage the pulsator was electrically driven and Bragg emphasised that this meant it was 'practically noiseless' - especially when compared with the Drinker machine, which was notoriously loud. ${ }^{67}$ Its externally audible noisiness was amplified further for users in the iron lung, who could also feel the pump vibrations. Thirteen pulsators were installed in British hospitals by 1937 (a further six were sent overseas), and another sixteen were on order. ${ }^{68}$ Even more were placed on backorder, perhaps because in 1938 there were several polio outbreaks and an increased number of diphtheria cases requiring ventilators.

The pulsator's highest-profile promotion was given by the $\mathrm{BBC}$ on a Friday night on 8 July 1938. The BBC sent out an emergency SOS for a Bragg-Paul pulsator needed at an Ipswich hospital to save the life of a child. ${ }^{69}$ One was immediately sent by car from a London hospital, but the patient died while it was in transit. ${ }^{70}$ On 14 July 1938, this case was discussed in the House of Commons and the Minister of Health was asked whether he could provide more pulsators to hospitals throughout Britain to extend coverage from the eighteen 
already in use. ${ }^{71}$ Similarly, on 24 July 1938, a fifty-eight-year-old man died in the Royal Infirmary in Liverpool after a plane was sent to rush a Bragg-Paul pulsator from Ipswich to Liverpool. ${ }^{72}$ Presumably the respirator had been in Ipswich since it had earlier been sent from London, and it was immediately sent back by train for another ill patient. Such well-publicised crises led to huge media interest but there was some initial confusion in the British press between the Drinker apparatus and the pulsator. Paul hastened to write to Dr Sommerville Hastings following the broadcast to explain the advantages of the pulsator, explaining 'I, personally, find it hard to imagine the continuous use of the other type for three years on a patient. ${ }^{73}$ However, Hasting replied that the Drinker machine was thought by physiologists to be better because it used negative pressure (creating a vacuum), which more closely imitated natural breathing. ${ }^{74}$

Head- and chest-only machines (like the Bragg-Paul) meant that the user was less restricted and more independent. Yet its manner of working (using positive pressure) was of concern to some medics, who highlighted the increased risk of cardiovascular problems resulting from reduced circulation and blood pressure. ${ }^{75}$ Its unusual invention and the involvement of an engineer was also considered suspect by certain medical professionals.

A film made in the 1940s to demonstrate the different mechanical methods of artificial respiration shows how different the Bragg-Paul pulsator looks in use compared to the fully enclosed machines. ${ }^{76}$ The film begins with the opening intertitle ' 1 . The Paul-Bragg pulsator. The chest is rhythmically subjected to positive pressure.' After showing the working of the machine the camera focuses in on a white-coated doctor wrapping the waistcoat around a bare-chested man and securing it before plugging him into the pulsator beside the bed. The man's chest moves up and down dramatically in a wavelike motion and it almost seems as if there is something trying to escape from under his skin. This method seems almost animalistic compared with the other artificial methods shown. When the doctor covers the patient with a shirt and leaves the waistcoat on underneath it is clearly much less obtrusive. The way that it made visible so clearly the process of forced breathing, without the apparent security and concealment offered by the more technologised devices, was uncomfortable to watch. For me, it gave quite a different impression of the Bragg-Paul pulsator compared to the textual primary sources I had so far been reliant on and it made me feel more sympathy with the physiologists who argued against its use as 'unnatural'. I found myself unconsciously holding my breath while watching it and becoming increasingly conscious of my own breathing. 


\section{Patient experiences in the machine}

The debate over negative versus positive pressure led to the MRC appointing a committee to investigate the best mechanical apparatus for 'preventing asphyxia due to respiratory paralysis. ${ }^{77}$ This MRC intervention was designed to fix on a standard machine for artificial respiration. This intervention was facilitated by a 'Respirators (Poliomyelitis) Committee' which comprised eight medical professionals who planned to compare the advantages of the different mechanical respirators then available. ${ }^{78}$ The committee was especially interested in whether negative or positive pressure was preferable for artificial respiration and considered a wide variety of what they termed, 'breathing machines'. As well as considering the division between negative and positive pressure, the committee was also concerned with whether full body enclosure machines or head-and chest-only enclosure-style devices were preferable. This subject demanded immediate attention, as a serious polio epidemic had hit England and Wales in $1938 .^{79}$ Patients and users were explicitly not considered as possible members of this committee, which was convened to 'examine the various forms of machine available and to consider the problem from the physiological point of view. ${ }^{80}$ Initially, the committee aimed to evaluate whether negative or positive pressure was best for artificial respiration and therefore conclude whether the Bragg-Paul pulsator or the iron lung device should be recommended as standard. However, the variability of respiratory conditions under consideration and the complexities of individual cases meant that the report expanded to consider a wide variety of respiratory conditions and a wide variety of so-called 'breathing machines'. This section will argue that the heterogeneity of the conditions that required such machines, combined with the individual nature of breathing, conflicted with the MRC's remit to standardise breathing machine usage.

The committee divided power-driven machines into three categories: first, machines that enclosed the full body of the patient; second, machines that enclosed the body and head; and finally machines that did not involve total enclosure of the body. These categories suggest how bodily autonomy and movement of the patient was factored into consideration of the usefulness and effectiveness of the machines. The Barospirator was invented in 1906 and was the only device that enclosed both the body and the head. It worked like the aforementioned oxygen rooms, through strict atmospheric controls applied to a large chamber which the patient and up to two others could remain in. The control of carbon dioxide this necessitated was considered by the committee to be too onerous and so this invention was not given detailed consideration. 
Thus, the main debate was over full body enclosure or not. Full-body enclosure devices included: the Drinker respirator, the Drinker-Collins respirator, the Emerson respirator, the Henderson respirator, the Siebe-Gorman 'Drinker' respirator and the Both respirator. Devices that worked without full body enclosure included: the 'Biomotor' of Dr Eisenmenger, the Bragg-Paul pulsator, the Burstall jacket respirator, the London County Council Cuirass respirator, the Turner jacket respirator, the Laffer-Lewis apparatus and Eve's Motor Rocking Bed. The latter worked on a different principle from the others: rather than using negative or positive pressure, it used gravity and the weight of the patient to force their diaphragm to move in and out. Such rocking beds were used regularly in the US on partially paralysed polio patients, but this one was presumably included under power-driven machines because it used an electronic motor to rock the bed. ${ }^{81}$ Historian Dora Vargha has vividly explained how full-body enclosure-style devices worked in practice.

The patient lay on her back, her whole body inside the machine, with only her head on the outside. The machine created a vacuum inside the tank, which made the patient's chest rise, resulting in inhalation. The pressure then changed in the tank, letting the chest fall and creating exhalation. ${ }^{82}$

The MRC report contains a section devoted to 'preparing the patient for the machine', which indicated what kind of clothes the patient should wear in this kind of device (see Figure 6.1). Only pyjama trousers and an undervest were allowed until the patient was secured inside the machine and then the pyjama jacket was put on back to front to avoid skin irritation from the rubber neck-hole rubbing against the neck. ${ }^{83}$ The boxes used in Britain were typically made of plywood ('iron lung' was technically a misnomer) and so a thin layer of cotton wool was applied (and held in place with a bandage) to avoid skin irritation. It was crucial that 'bedsocks' were worn to avoid chilled feet from the air that rushed in from the suction hole at the end of the machine, and blankets were strategically placed to prevent patient complaints of 'cold spots' and to avoid bed sores. Careful consideration of clothing and the handling of the patient was important because of patient complaints of extreme tenderness and 'hyperaesthesia' (excessive skin sensitivity), which could make any handling very painful and distressing. ${ }^{84}$ Adjusting the temperature of the patient within the machine was clearly an issue of some concern, and heated lamps within the cabinet were utilised alongside hot-water bottles and bellows (for cooling). Learning to eat and drink also required adjustment, as users had to learn how to adjust their swallowing to fit with the rhythms of the machine. ${ }^{85}$ This was memorably described by home ventilation user David Brooks in 1990. Though Brook's assessment came much later than the MRC report, it 


\section{Plate I}
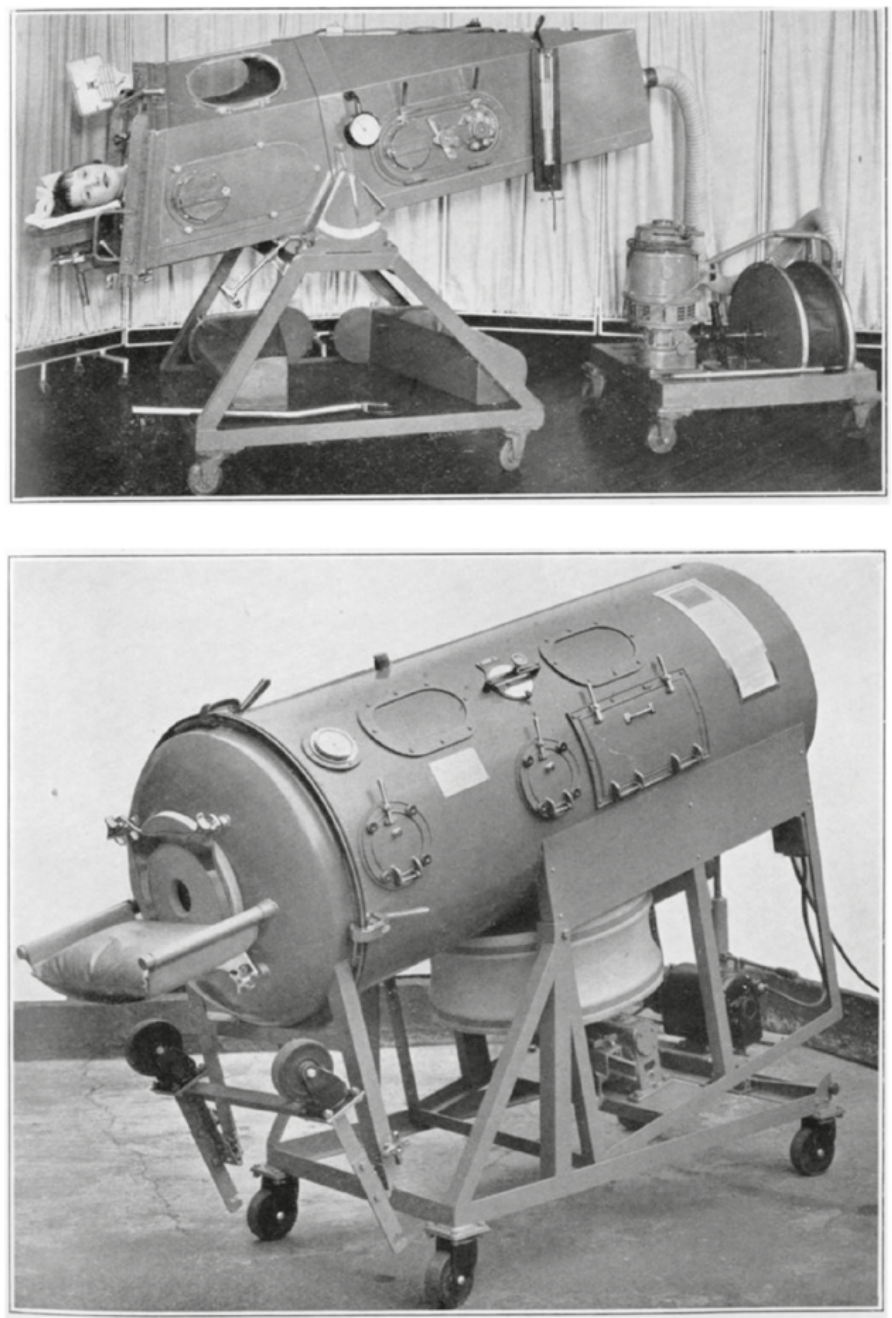

Figure 6.1 Drinker respirator and Drinker-Collins respirator

vividly portrays the difficulties associated with returning to normal activities while on breathing support.

In addition to breathing, body movements, walking and talking, the most energy sapping activity is surprisingly eating. Having lost so much weight following lung cancer, the removal of my right lung and radiotherapy, it rather added 
insult to injury to find that the mechanics of eating, swallowing and digesting so intimately involved the respiratory system. Exhausted swallowing muscles and pain filled chest muscles convulse along with my uselessly flapping diaphragm. They are my accompaniments to meal times, a constant battle ground between the requirements of nutrition and the insistent distress of respiratory despair. ${ }^{86}$

The MRC report also highlighted significant concerns about how best to synchronise an individual's breathing with the rhythm of the machine. If conscious, patients could 'frequently' indicate what pressure felt most comfortable and best matched their personal breathing rate. ${ }^{87}$ This did not always lead to a perfect fit, as:

The Patient's breathing will usually be, for a short time, irregular and 'out of step' with the regular breathing of the machine, but cases with respiratory insufficiency readily adapt themselves to the rate of the machine. If the patient's breathing persistently fails to synchronise, it means that he has an adequate power of natural breathing and does not require treatment in the machine. ${ }^{88}$

This quotation reveals the difficulty inherent to standardising measures for a process as individual and variable as breathing. Moreover, the suggestion that users adapt themselves to the machine suggests that users were required to modify themselves to fit the technology, rather than the other way around. If patients were continually unable to adapt themselves in this way or were apprehensive of doing so, their breathing rate was adjusted slowly and without their knowledge. ${ }^{89}$ Similar tactics were used to wean 'nervous' patients off the machines by tricking them into believing the machine was still working: 'the pressure can, without their knowledge, be gradually reduced until finally the motor is running but no negative pressure is being produced. ${ }^{90}$ More resistant patients were simply given a sedative to force their cooperation: 'sedatives are not required for long, as most patients soon learn to co-operate with the machine. ${ }^{91}$ Clearly, there was awareness of how distressing these breathing machines could be for users. However, the report insisted that for seriously ill patients, 'the relief afforded is so great and so sudden that any psychological stress is quickly banished. ${ }^{92}$ Perhaps surprisingly given Bragg's reference to noise as a problem, the rhythmical noise of the motor was suggested in the report to be soothing and conducive to deep sleeping. This assessment was a marked contrast to Brooks's (admittedly much later) description of sleeping in an assisted ventilation unit: 'the noise at night of all these pumps, huffing and puffing, inevitably at different tempos, was rather like a poorly syncopated orchestra with a demented wind section. ${ }^{93}$

Moreover, the MRC's optimistic analysis was not wholly supported by the details provided in the appendix to the report, which provided quantitative and qualitative details in relation to individual case reports from across the 
UK involving use of the Drinker respirator and the Bragg-Paul pulsator. ${ }^{94}$ There were repeated instances of user rejection in these tables. For instance, one patient survived treatment with the 'Both'-type machine but 'objected strongly to being put in it. ${ }^{95}$ One patient used the Bragg-Paul pulsator but 'tended to breathe against it' and died after a day of its use. Similarly, another user of the pulsator had difficulty adjusting to its breathing rate: 'Difficulty in synchronisation of artificial and natural respiration caused discomfort and led to cessation of treatment. ${ }^{96}$ Many patients simply refused to use the machines, and though some survived, in other cases this refusal was noted as contributing to their death. In certain cases, the patient is simply noted as finding the machine either a source of 'relief' or as 'uncomfortable', though one specific case noted 'discomfort in machine so severe that patient's removal from it was ordered.$^{97}$ Another patient was described as 'so terror-stricken by machine that he had to be removed.$^{98}$ Comparing the images from the report (shown here as Figure 6.1 and Figure 6.2) might provide clues to explain this reaction. While the Burstall jacket respirator and the Bragg-Paul pulsator do look strange, with the latter resembling diving apparatus (unsurprising given that the manufacturing company Siebe-Gorman specialised in diving apparatus), they clearly allow for movement and control; on the other hand, the Both-style iron lung resembles, more than anything else, a coffin. Overall, the impression of user experience of these 'breathing machines' was highly variable. And, crucially, the user's inability or unwillingness to use the machines was a repeated motif and clearly affected the viability of this kind of treatment.

One key appeal of the pulsator was that while wearing it, the patient was not hindered or inconvenienced by its movements. With an attachment, it could also be used by two patients at the same time, forcing them to literally conspire together. ${ }^{99}$ However, there was concern that positive pressure respiration could depress circulation and reduce cardiac output and blood pressure, a concern which was heightened for bulbar polio patients suffering from circulatory damage. ${ }^{100}$ It was crucial then, the MRC decided, for patients using an artificial respirator to be under the expert management of doctors, nurses and other attendants who were 'acquainted with certain points and difficulties which arise during the use of mechanical aids to respiration', especially when repair was required. ${ }^{101}$ The MRC report emphasised that those using such machines must only do so under the supervision of medical professionals. ${ }^{102}$ Care was also necessary to ensure that infections, bed sores, vomiting and constipation were managed so as not to cause serious complications, especially in patients with respiratory paralysis.

The MRC report on 'Breathing Machines and their Use in Treatment' was published in 1939, just as William Morris, later Lord Nuffield (1877-1963), 


\section{Plate III}
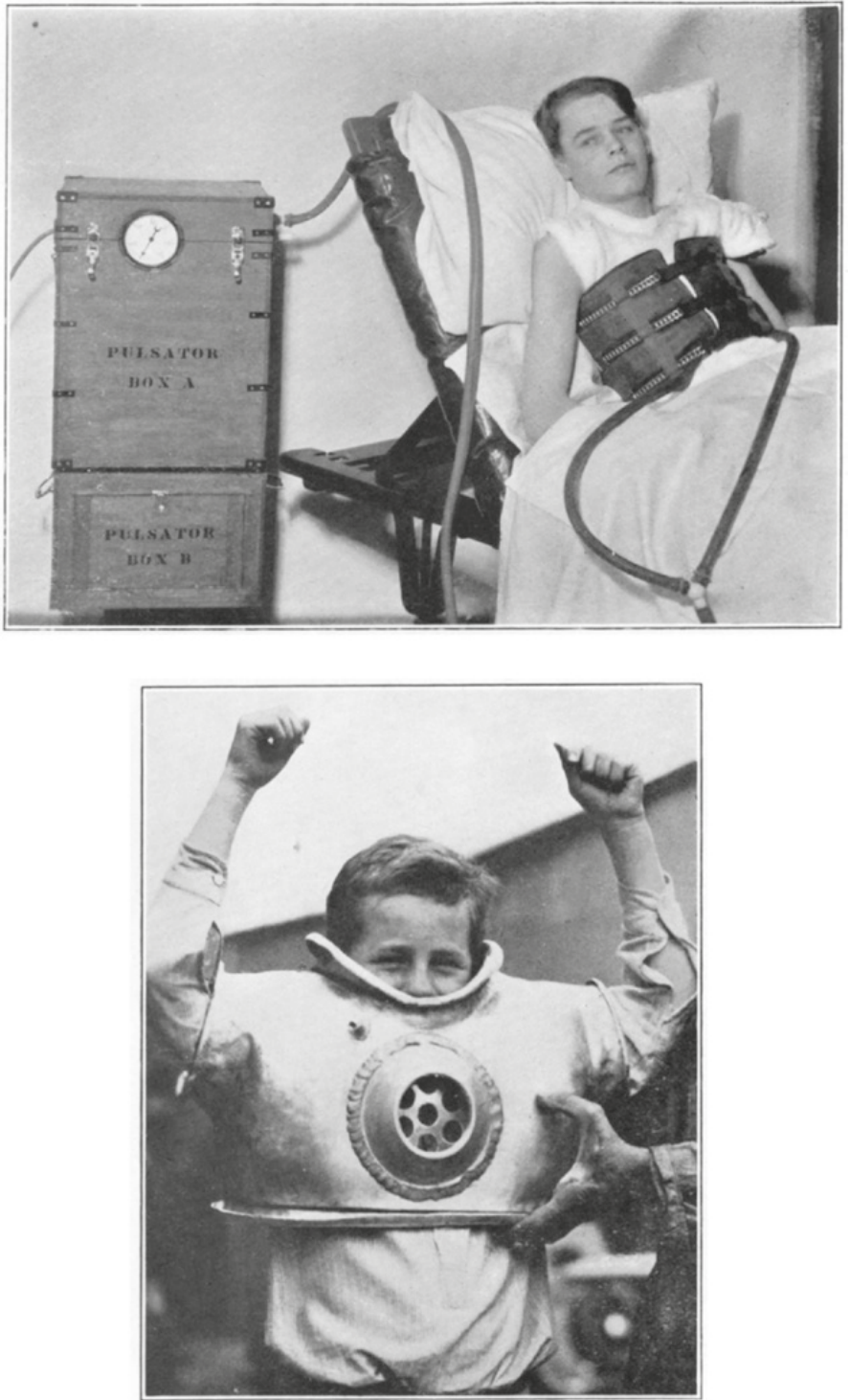

Figure 6.2 Bragg-Paul pulsator and Burstall jacket respirator 
announced his intent to widely distribute 800 Both-style respirators around Britain, free of charge. Morris manufactured the iron lungs in his car factories and eventually donated more than 5,000 of these devices. ${ }^{103}$ The donation of iron lungs to hospitals throughout Britain allowed for free and easy institutional usage, especially as the MRC recommended that it was more beneficial to bring patients to the hospital than to bring equipment to the home. By the end of March 1939, there were just over 1,000 respirators in the British Isles: 965 Both respirators, 43 Bragg-Paul pulsators and 30 Drinker machines. ${ }^{104}$

\section{From home to hospital}

Bringing patients to the hospital and placing them in these machines became standard practice after the Second World War. However, this solution (while medically and economically advisable) could lead to added distress to families, who lost the ability to communicate with their loved ones. Not only were patients quarantined (physically isolated), it was also difficult for them to communicate with the medical team as a result of their encasement and reduced visibility in the iron lung. Literally, this encasement impeded patient voice, as they could only talk on the out-breath of the machine. We can determine the practical consequences of such isolation from cases like that of sixteen-yearold Dorothy, who woke in the night of 28 September 1950 with severe back pain. ${ }^{105}$ Over the next two days her pain worsened, until she was vomiting from agony and forced to go to hospital. The attending doctor noted that she had widespread paralysis and diagnosed APM (acute poliomyelitis). Her subsequent isolation caused severe anxiety to her mother, who wrote to the hospital to explain:

[W] hen Dorothy was taken away I had 2 shocks first was to be told by her own

Dr, that Dorothy was 10 weeks pregnant, second was to hear she had Polio, this has drove me nearly crazey [sic] with worry, as Dorothy was in such awful pain I decided not to say anything to her about being pregnant until she was better, but instead she got worse and was taken away. ${ }^{106}$

The physician treating Dorothy replied somewhat caustically that 'I can hardly doubt but that Dorothy knows quite well that she is pregnant', but reassured her mother that the paralysis was improving, and that Dorothy had not lost the baby. However, by the end of November he decided that it was necessary to terminate the pregnancy to save the patient. After this, Dorothy's condition rapidly improved, she was able to undergo physiotherapy and after ninety-four days in hospital, she was discharged. Although her experience was 
undoubtedly traumatic for her and her family - she was described twice in the notes as hysterical - Dorothy's case at least ended with recovery.

By contrast, twenty-nine-year-old polio patient Rose was admitted to the same hospital on 16 October 1950 and was immediately placed in a mechanical respirator. ${ }^{107}$ Her abdominal reflexes were described as 'absent' and she had 'little movement' in her diaphragm. Her distress was such that she was only partially examined before being placed straight into the respirator. Once in the respirator, she was given physiotherapy 'in so far as can be managed with patient in respirator. ${ }^{108}$ By December, she could be taken out of the respirator for controlled periods, only initially managing two to three minutes but up to four to five minutes by the end of the month. On 31 December 1950 there was an electricity failure in the hospital which meant Rose 'almost died' before it was possible to get the 'manual operation working. This may be the reason that six days later she was transferred from the Drinker respirator to the Both respirator - a change which made her both more cheerful and comfortable. However, over the following month she contracted pneumonia and, despite rallying towards the end of January, she had a 'sudden attack of dyspnoea' (breathlessness) at midnight on 1 February 1951, became unconscious, was briefly revived and described as 'terrified', before she subsequently died. ${ }^{109}$

The practice of gradually building up the time the patient spent breathing unaided outside the respirator was a standard treatment for polio patients with respiratory paralysis, especially as it allowed them to participate in physiotherapy. Patients using the respirator were encouraged to stay out for longer periods and once they could remain out for forty-five minutes, they started taking their meals outside the machine. Although adult patients were relatively isolated and relied on epistolary correspondence to communicate with the outside world, parents were able to visit younger children living in the iron lungs, often for extended periods. One such child patient spent 218 days in this hospital in the Drinker machine. When he died, the attending physician described it as a 'welcome event', noting that he 'would never have lived independent of respirator' but that he was 'quite cheerful up to end. Parents helped a great deal by visiting daily without fail. ${ }^{\prime 10}$ The child's GP agreed with this assessment and wrote to the hospital physician to thank him for his care, noting 'I agree with you that it was the best thing that could have happened to the poor child, under the unhappy circumstances."111 These notes illuminate the changing conception of the respirator, from a prosthetic enabling the user to continue life at home, to emergency hospital equipment in which life was considered untenable. Even though these patients were described as cheerful, the iron lung was not being used in the hospital as a prosthetic in the way that Halahan had used his pulsator at home. However, there is evidence that some 
contemporary users were using iron lungs to live full and productive lives in this period, as in the case of Mr Fred Suite, who lived in an iron lung when he was married in 1939 and went on honeymoon in a specially weight-adapted trailer. ${ }^{112}$

Furthermore, there are accounts of users of iron lungs and their family members designing home-made personalised machines during this period in Britain. For instance, in 1949 Mr A. F. Evans, a motor engineer in Coventry, designed a specific style of iron lung for his daughter which would allow her to live at home. He explained that he had built the device in his garage with some assistance from his employees and his daughter's friend, and emphasised that 'This new lung I have made covers only the abdomen and chest. It keeps Ann breathing and allows the physiotherapist to give massage and to exercise the limbs to bring fresh life into them.' ${ }^{113}$ A twenty-six-year-old man in Essex who had virtually no movement except of his head and neck lived at home and was reported to 'frog-breathe for up to three hours but otherwise needs a Tunnicliffe respirator and pump. ${ }^{114}$ In a letter to the editor of The Lancet, his doctor detailed the different organisations involved in his care, which included the installation of a Post Office telephone; the doctor explained that "The County Health Department provide a special nurse; the local council have altered the house; the GPO installed a telephone within 24 hours; the next-door neighbour services the pump; and the Association for the Physically Handicapped have helped in many ways.' ${ }^{115}$ Bess Williamson has explored similar instances of users of respiratory technology appropriating medical prothesis to their own designs, by altering 'familiar technologies to work for their own disabled bodies.' ${ }^{116}$ In Williamson's analysis of post-1950s magazines for selfnominalised 'respos', she finds that the equipment that disabled users ordered from hospitals often failed to integrate into their users' lives and required individual adaptation and 'tinkering'. Despite the wide acknowledgement of this tinkering in the disabled community in the US, respiratory technology designers did not advertise to users and the medical establishment ignored patient input in this arena. ${ }^{117}$

In part, such individualistic 'tinkering' may have stemmed from the specific nature of individuals' breathing preferences. While some users emphasised the greater portability and independence that chest-only devices offered, others preferred the all-encompassing relief offered by the standard iron lung's negative pressure. For example, Marshall Barr developed polio in Britain in 1949 and began using an iron lung in 1971. He described the experience of encasement as a 'relief' and highlighted the relaxing qualities of its sounds and vibrations, 'like: ... breathing, bump; breathing, bump ... It was not quite like a smooth breath.' ${ }^{118}$ Paul Alexander, who started using an iron lung in 1952, used 
it in his university dorm in the US to pursue a successful career as a lawyer and remains in the machine at the time of writing. ${ }^{119}$ In 2017, Martha Lillard, one of three people still using iron lungs in the US described how the lung provided relief by taking away the effort of breathing for her: 'Imagine if you were real tired of breathing, how good that would feel - if you were struggling to take a breath. ${ }^{120}$ For Martha and others still reliant on these older technologies, one of the main challenges is finding technicians willing to repair the iron lungs, as the private companies which originally designed them no longer take responsibility for maintaining them. ${ }^{121}$

As this chapter has emphasised, the heterogeneity of respiratory disability experiences proved challenging for the development of standardised treatments. This historical analysis highlights the importance of prioritising patient voices today, especially when making judgements about quality of life. Caution in this respect is highlighted by 'the disability paradox' explored in Chapter 2. That is, the fact that many disabled people rate their quality of life as good or excellent although external observers imagine them to have an 'undesirable daily existence.' ${ }^{122}$ When asked to imagine the well-being of disabled people, non-disabled people tend to imagine it to be far worse than it is, and this error is exacerbated if the non-disabled person is a healthcare professional and corrected if they have spent time with disabled people. Given these findings, this historical episode highlights the crucial importance of making patient voices central, and especially disabled voices, in all discussions about prosthetic technology.

\section{Conclusion: the ergodic switch}

In the late 1800s, physicists working with gases encountered a measurement problem that is especially pertinent to the concerns of this chapter and the overall message of this book. While these physicists could easily measure the collective qualities of a group of gas molecules, identifying the specific features of each individual molecule proved challenging. To meet this challenge, the measurers decided to 'use the average behaviour of a group of gas molecules to predict the average behaviour of a single gas molecule. ${ }^{123}$ In doing so, they invoked a set of mathematical principles known as ergodic theory. As Todd Rose explains: 'According to ergodic theory, you are allowed to use a group average to make predictions about individuals if two conditions are true: (1) every member of the group is identical, and (2) every member of the group will remain the same in the future. ${ }^{124}$ As it turned out, most gas molecules did not conform to these rules, and, as this chapter has outlined, neither do most people. Yet using group averages to measure and assess individuals as though 
they are ergodic is precisely how we have calculated the thresholds of normalcy in a variety of statistical studies about human abilities. The idea that people can be ranked as though identical and immutable has been dubbed 'the ergodic assumption' by Peter Molenaar, who explains that 'using a group average to evaluate individuals would only be valid if human beings were frozen clones, identical and unchanging. ${ }^{125}$ As this chapter has outlined, using the measurements of a group to standardise technologies for individuals that are part of that group has led to user modification and rejection of assistive technology.

The nine patients of Brompton hospital that we discussed in the introduction to this chapter believed that they felt better as a result of their experience in the air baths. Fundamental to knowledge of health and illness is this precise question: how do you feel? But how do you know how you feel? Bodily intuition was traditionally relied upon, but over the course of the twentieth century, the veneration of numerical data as a guide to our bodies has superseded embodied knowledge. Such a position suggests that numbers and quantified data are understood to be neutral, objective and valid in a way that lived experience is not. Many have criticised this suppression and dismissal of bodily intuition as inherently reductionist, arguing that important personal perspectives are being discounted. I have argued here that this can also create mechanical epistemic injustice, which has especially deleterious impacts on the disabled.

This is an issue that is exacerbated in cases of invisible disability and further intensified by the multidimensional nature of breath, which resists reductive measurement approaches. As I have shown in this chapter, attempts to establish a standard 'breathing machine' eluded the MRC as it struggled to catch the breath of the idiosyncratic individuals under their investigation. In contrast, by working closely with a user, William Bragg and Robert Paul's design prioritised the goals and priorities of the intended consumer. Yet this meant that their design needed essential modifications (made by medical professional Dr Phyllis Kerridge) before it could be standardised for a variety of bodies in a hospital setting. Yet as standardised respiratory technologies moved from the home to the hospital and back out again, individual users made modifications to their design to suit themselves. As I argue here and elsewhere in this book, the distinctive kind of embodied knowledge that the disabled have about their own bodies resulted in innovation and invention during the interwar period. Technologies designed by individuals for individuals could be surprisingly successful. Ironically, the individual nature of this insight can work as a barrier to standardised usage (as we see in the case of the pulsator versus the iron lung). The kind of standardised usage that is necessary for institutional use in hospital settings meant that patients had to increasingly adapt to the machines they were placed in. Yet users often resisted this kind of technological intervention. 
Such experiences have not been entirely relegated to the domain of history, as the kind of mechanical ventilation commonly used in intensive care units can now be done while patients are still conscious, and the experience of being unable to control one's own breathing or to speak has been recently found to result in panic, fear and enduring anxiety. ${ }^{126}$ Moreover, original embodied knowledge often becomes invisible when embedded in technological designs or is lost with the individual or with the end of company involvement - a situation which points to the danger of privatising life-saving devices. If the insights of intended users were embedded at the start of the design process through co-production efforts then the inevitable user rejection and modification of assistive technology could be avoided and the end product would, no doubt, be much improved.

\section{Notes}

1 Wallis, J., 'A Machine in the Garden: The Compressed Air Bath and the NineteenthCentury Health Resort', in J. Agar and J. Ward (eds), Histories of Technology, the Environment and Modern Britain (London: UCL Press, 2018), pp. 76-100, p. 83.

2 Ibid.

3 G. E. Beaumont, 'The Effect of Compressed Air Baths upon the Vital Capacity in Emphysema', in Brompton Hospital Reports, vol. 6, 1937. Royal London Hospital Archives, London, RLBH/A/13/63, p. 118.

4 Ibid.

5 Ibid., p. 120.

6 Ibid.

7 McGuire and Carel, 'The Visible and the Invisible'.

8 For a full explanation of the building of the Bragg-Paul pulsator see McGuire, C., Virdi, J., and Hutton, J., 'Respiratory Technologies and the Co-Production of Breathing in the Twentieth Century', in A. Hanley and J. Meyer (eds), Patient Voices (Manchester: Manchester University Press, forthcoming). Some of the material in the sections on 'The origins of pneumatic medicine' and 'The Bragg-Paul pulsator' originally appeared in that chapter and is reproduced here with permission.

9 Binnie, K., McGuire, C., and Carel, H., 'Objects of Safety and Imprisonment', Journal of Material Culture (under review).

10 Ibid.

11 For an earlier history of artificial respiration, see Barrington, A. B., 'Artificial Respiration, the History of an Idea', Medical History, 15:4 (1971), 336-351.

12 Chang, H., 'The Hidden History of Phlogiston: How Philosophical Failure Can Generate Historiographical Refinement', HYLE: International Journal for Philosophy of Chemistry, 16:2 (2010), 47-79, p. 71.

13 Jackson, J., A World on Fire: A Heretic, an Aristocrat, and the Race to Discover Oxygen (New York: Viking, 2005), p. 126. 
14 McEvoy, J. G., 'Gases, God and the Balance of Nature: A Commentary on Priestley (1772) "Observations on Different Kinds of Air"', Philosophical Transactions of the Royal Society A: Mathematical, Physical and Engineering Sciences, 373:2039 (2015), $1-11$, p. 4.

15 Jackson, A World on Fire, pp. 169-170.

16 Joseph Priestley, quoted ibid., p. 172.

17 Miller, D. P., and Levere, T. H., “'Inhale It and See?”: The Collaboration between Thomas Beddoes and James Watt in Pneumatic Medicine', Ambix, 55:1 (2008), 5-28.

18 Grainge, C., 'Breath of Life: The Evolution of Oxygen Therapy', Journal of the Royal Society of Medicine, 97:10 (2004), 489-493.

19 Miller and Levere, “"Inhale It and See?”, pp. 7-8.

20 Ibid.

21 Leigh, J. M., 'The Evolution of Oxygen Therapy Apparatus', Anaesthesia, 29 (1974), 462-485.

22 However, use of a mouthpiece required willing cooperation and when oxygen began to be used as an anesthetic from the 1840 s, face masks were developed to fully cover the mouth and nose. See ibid.

23 Beddoes, T., and Watt, J., Considerations on the Medicinal Use and Production of Factitious Airs, part 3 (Bristol: Bulgin and Rosser, for J. Johnson, London, 1795), University of Bristol Library Special Collections.

24 Ibid., p. 30.

25 Ueyama, T., Health in the Marketplace: Professionalism, Therapeutic Desires, and Medical Commodification in Late Victorian London (Palo Alto, CA: Society for the Promotion of Science and Scholarship, 2010). From 1868, compressed oxygen gas could be stored in cylinders and this removed the need for the physician to manufacture oxygen on an individual basis. See Leigh, 'The Evolution of Oxygen Therapy Apparatus'.

26 Heggie, V., 'Experimental Physiology, Everest and Oxygen: From the Ghastly Kitchens to the Gasping Lung', British Journal for the History of Science, 46:1 (2013), 123-147.

27 Except in home remedies and 'quack medicine'. See Ueyama, Health in the Marketplace.

28 'Editorial: The Therapeutic Use of Oxygen', Canadian Medical Association Journal, 16:6 (1926), 696-697, and Grainge, 'Breath of Life', p. 491.

29 It was manufactured by Messrs Siebe, Gorman \& Co. in London. See Davies, H. W., 'Methods for the Therapeutic Administration of Oxygen', Edinburgh Medical Journal, 29:5 (1922), 161-168, p. 166.

30 This method was described as follows: 'the patient's head is enclosed in a cardboard hat box of suitable size, a suitable opening being cut for the neck, and the stream of oxygen being directed into the box'. See Davies, 'Methods for the Therapeutic Administration of Oxygen'.

31 Stadie, W. C., 'Construction of an Oxygen Chamber for the Treatment of Pneumonia', Journal of Experimental Medicine, 35:3 (1922), 323-335, p. 326. 
32 Barcroft, J., 'Discussion of the Therapeutic Uses of Oxygen', Proceedings of the Royal Society of Medicine, Section of Therapeutics and Pharmacology, 13 (1920), 59-68.

33 Davies, 'Methods for the Therapeutic Administration of Oxygen'.

34 Laing, G. D., 'The Administration of Oxygen', British Medical Journal, 1:3311 (1924), 1074-1075.

35 Ibid.

36 Ibid.

37 Ibid.

38 Bert's experiments on sparrows first demonstrated this; see Heggie, 'Experimental Physiology, Everest and Oxygen'; and cf. Binger, C. J., Faulkner, J. M., and Moore, R. L., 'Oxygen Poisoning in Mammals', Journal of Experimental Medicine, 35:5 (1927), 849-864, and Evans, J. H., 'The Inhalation of Pure Oxygen in the Treatment of Disease', Canadian Medical Association Journal, 22:4 (1930), 518-522.

39 For a full discussion of the process of the Bragg-Paul pulsator's invention see McGuire et al., 'Respiratory Technologies'.

40 Bragg described Halahan as his friend and 'neighbour in the country'. Bragg was working in London at this time but may have had a second home/main base in West Sussex. Letter from W. H. Bragg to Leonard Hill, 4 January 1934. Royal Institution of Great Britain, London, William Henry Bragg RI Admin. Correspondence 1933-39 (hereafter WHB), RI MS WHB/27E/5. Information on Samuel Crosby Halahan was retrieved from GENi. www.geni.com/people/Samuel-Halahan/ 6000000015282798567 . Accessed June 2019.

41 Letter from Bragg to Hill, 4 January 1934.

42 Kerridge, P. M. T., 'Artificial Respiration for Three and a Half Years', The Lancet, 227:5870 (1936), p. 504. The discussion of the nurses' continuous artificial respiration is discussed in a newspaper clipping titled 'Iron Lungs'. Royal Institution of Great Britain, William H. Bragg Miscellaneous Correspondence (hereafter WHBMC), Bragg-Paul Pulsator (15 March-15 August), RI MS WHB/8B/9. See also: Blackwell, U., 'Mechanical Respiration', The Lancet, 254:6568 (1949), 99-102.

43 Paul was internationally renowned for his scientific instruments, including the galvanometer, early wireless telegraphy sets and devices for submarine warfare; he is also famous today as a pioneer of British film, devising cameras and projectors for motion pictures.

44 'Iron Lungs'. WHBMC.

45 Bragg, W. H., 'Bragg-Paul Pulsator', British Medical Journal, 10:1136 (1938), 254.

46 Letter from Bragg to Hill, 4 January 1934.

47 Bragg, 'Bragg-Paul Pulsator'.

48 Copy of letter from William H. Bragg to Secretary of the British Red Cross Society, addressed to Colonel Day, 11 July 1938. WHBMC, WHB/8B/4-5. The Red Cross was also interested in Bragg's creation, especially since that organisation helped to commercialise oxygen tents, as indicated by a letter of 17 July 1938 from Sir Harold B. Facus, the Director-General of the British Red Cross Society to Bragg. WHBMC, $\mathrm{WHB} / 8 \mathrm{~B} / 6$. 
49 'Iron Lungs'. WHBMC.

50 McGuire and Carel, 'The Visible and the Invisible'.

51 Bragg, 'Bragg-Paul Pulsator'.

52 Oshinsk, D. M., Polio: An American Story (Oxford: Oxford University Press, 2006), p. 61.

53 Ibid.

54 The device was originally requested by the South Australian Government in 1938 to combat a devastating poliomyelitis epidemic.

55 Drinker, P., 'Prolonged Administration of Artificial Respiration', The Lancet, 217:5622 (1931), 1186-1188.

56 The attendant was also essential for enabling toilet function, through bedpans and enemas. Ibid.

57 Barr, M., 'The Iron Lung: A Polio Patient's Story', Journal of the Royal Society of Medicine, 103:6 (2010), 256-259, p. 256.

58 'Iron Lungs'. WHBMC.

59 Kerridge, 'Artificial Respiration for Three and a Half Years'.

60 This technique is called glossopharyngeal breathing. See Wilson, D. J., Living with Polio: The Epidemic and Its Survivors (Chicago: University of Chicago Press, 2005), p. 91.

61 Letter from K. N. Knapp to William Bragg, 18 September 1933. WHB 27E/4.

62 Poulton also invited Bragg and Paul to present their device to the Therapeutic and Pharmaceutical Section of the Royal Society of Medicine.

63 For more on the development of the pulsator and the role Dr Phyllis Kerridge played in its development see McGuire et al., 'Respiratory Technologies'.

64 Letter from Bragg to Secretary of British Red Cross Society.

65 Letter from William Bragg to S. C. Dyke, 7 June 1934. WHB 27E/20.

66 Letter from Siebe-Gorman \& Co. Ltd to Robert W. Paul, 21 May 1936. WHB 27E/ 29.

67 The same company that designed the oxygen mask equipment. Bragg, 'Bragg-Paul Pulsator', p. 254. On the noisiness of the Drinker machine see Gilbertson, A. A., 'Before Intensive Therapy?', Journal of the Royal Society of Medicine, 88:8 (1995), 459-463, p. 461.

68 Letter from Robert Paul to Dr J. R. Hutchinson, Deputy Senior Medical Officer, Ministry of Health, 12 August 1938. WHB 8B/24-26. Pulsators were distributed to hospitals in Manchester, Birmingham, London, Norwich, Ipswich, and Liverpool.

69 'Bragg Paul Respirator', HC Deb 14 July 1938, vol. 338, cc. 1517-1518. https://api. parliament.uk/historic-hansard/commons/1938/jul/14/bragg-paul-respirator. Accessed July 2019.

70 Letter from Robert Paul to C. J. McSweeny, 17 July 1938. WHBMC, WHB/8B/8.

71 'Bragg Paul Respirator', HC Deb 14 July 1938.

72 'Plane's Vain Dash with Respirator', The Scotsman, 25 July 1939. British Newspaper Archive, BL 0000540/19380725/107/0012. 
73 Letter from Paul to Dr Somerville Hastings, 2 January 1938 (re. BBC broadcast). Paul was sent the transcript by Bragg. WHB 27E/66.

74 Letter from Dr Somerville Hastings to Paul. WHB 27E/66.

75 Wilson, J. G., 'A Continuing Battle against the Virus of Polio', Municipal Journal, 59 (6 July 1951), 1577-1581, p. 1577 and p. 1581.

76 This film was made by Oxford University's newly instated (1937) Department of Anaesthetics and has been made available by Wellcome on YouTube. See www. youtube.com/watch?v=21PEC3ppStc and http://catalogue.wellcomelibrary.org/ record $=$ b1677731 S3. Accessed July 2019. It was probably designed to accompany Lord Nuffield's iron lung donation and the film is referenced in a letter explaining the donation of the iron lung to St Bart's hospital. See 'Gift of a Mechanical Respirator from the Nuffield Trust', 1939. St Bartholomew's Hospital Archives, London, SBHB MR/32/4.

77 Medical Research Council, 'Breathing Machines' and Their Use in Treatment: Report of the Respirators (Poliomyelitis) Committee (Medical Research Council Special Report Series, No. 237) (London: His Majesty’s Stationery Office, 1939). TNA, FD 4/237 (henceforth MRC, 'Breathing Machines'), p. 3.

78 Ibid.

79 'Review: Medical Research Council. Special Report Series no. 237', Indian Medical Gazette (1940).

80 MRC, 'Breathing Machines', p. 2.

81 Wilson, Living with Polio.

82 Vargha, D., Polio across the Iron Curtain: Hungary's Cold War with an Epidemic (Cambridge: Cambridge University Press, 2018), p. 60.

83 MRC, 'Breathing Machines', p. 46.

84 Ibid., p. 47.

85 Ibid., p. 51.

86 Brooks, D. H. M., 'Living with Ventilation: Confessions of an Addict', Care of the Critically Ill, 8:5 (1992), 205-207; cf. Brooks, D. H. M., 'The Route to Home Ventilation: A Patient's Perspective', Care of the Critically Ill, 6:3 (1990), 96-97.

87 MRC, 'Breathing Machines', p. 48.

88 Ibid.

89 Ibid., p. 52.

90 Ibid.

91 Ibid., p. 49.

92 Ibid.

93 Brooks, 'Living with Ventilation', p. 207.

94 That these were the only two machines that this kind of data was available for indicates that they were two most widely used machines in Britain at the time of the report's compilation.

95 MRC, 'Breathing Machines', Appendix, 'Table A - Continued', p. 76.

96 Ibid., p. 90.

97 MRC, 'Breathing Machines', Appendix, 'Table E - Continued', p. 88. 
98 Ibid., p. 89.

99 'Iron Lungs Will Help Save Midland Kiddies', Birmingham Gazette, 4 November 1938. British Newspaper Archive, BL 0000669/19381104/057/0004. Note that although the headline refers to iron lungs, it was a Bragg-Paul pulsator which was gifted. 'Iron lung' was often used in the popular press to refer to a variety of styles of respirators. Children could also be attached in groups to the iron lung. 'Conspire' as from the Latin conspirare, com (with, together) and spirare (to breathe) See entry for 'conspire' in Online Etymology Dictionary. www.etymonline.com/ word/conspire?ref=etymonline_crossreference. Accessed June 2019.

100 Wilson, 'A Continuing Battle'.

101 MRC, 'Breathing Machines', p. 43.

102 Ibid.

103 Hurley, S., 'The Man behind the Motor: William Morris and the Iron Lung', Science Museum Blog, 7 March 2013. https://blog.sciencemuseum.org.uk/the-manbehind-the-motor-william-morris-and-the-iron-lung/. Accessed June 2019.

104 Gilbertson, 'Before Intensive Therapy?', p. 462.

105 All patient names have been changed to preserve anonymity.

106 Ham Green Hospital, Bristol, Records of Poliomyelitis, Chicken Pox, Herpes, Zoster, Rubella, Mumps, 1951. Patient Reg No. 1236/50, letter to resident physician James Macrae inserted into patient records 10 January 1950 to 1 January 1951.

107 Ham Green Hospital, Bristol, Records of Poliomyelitis, Chicken Pox, Herpes, Zoster, Rubella, Mumps, 1951. Patient Reg. No. 1298/50, patient records 16 October 1950 to 2 February 1951.

108 Ibid.

109 Ibid.

110 Ham Green Hospital, Bristol, Records of Poliomyelitis, Chicken Pox, Herpes, Zoster, Rubella, Mumps, 1951. Patient Reg. No. 1360/50, patient records 30 October 1950 to 3 June 1951.

111 Ibid., Patient Reg. No. 1360/50, letter inserted from Gloucester Road surgery, 7 June 1951.

112 'Iron Lung Man Wed', Telegraph and Independent, Sheffield, 11 August 1939. British Newspaper Archive, BL 0000702/19390811/007/0001.

113 'Home-Made Iron Lung Speeds Girl's Recovery', Coventry Evening Telegraph, August 24 1949. British Newspaper Archive, BL 0000769/19490824/256/0017.

114 Graves, J. C., Letter to the Editor, 'Domiciliary Rehabilitation of the Respiratory Cripple', The Lancet, 274:7110 (1959), 1033.

115 Ibid.

116 Williamson, B., 'Electric Moms and Quad Drivers: People with Disabilities Buying, Making, and Using Technology in Postwar America', American Studies, 52:1 (2012), 5-30, p. 23.

117 Ibid., p. 11.

118 Barr, ‘The Iron Lung', p. 256. 
119 Brown, J., 'The Last of the Iron Lungs', Gizmodo, 20 November 2017. https:// gizmodo.com/the-last-of-the-iron-lungs-1819079169. Accessed June 2019.

120 Ibid.

121 Ibid.

122 Albrecht and Devlieger, 'The Disability Paradox', p. 977.

123 Rose, The End of Average, p. 63.

124 Ibid. See also, Molenaar, P. C. M., 'On the Implications of the Classical Ergodic Theorems: Analysis of Developmental Processes Has to Focus on Individual Variation', Developmental Psychobiology, 50:1 (2007), 60-69.

125 Interview, Peter Molenaar and Todd Rose, quoted in Rose, The End of Average, p. 63.

126 I am grateful to historian Oriana Walker, who made this point in her presentation at the recent History of Science Society meeting in Utrecht and pointed out the accompanying source, Karlsson, V., Bergbom, I., and Forsberg, A., 'The Lived Experiences of Adult Intensive Care Patients Who Were Conscious during Mechanical Ventilation: A Phenomenological-Hermeneutic Study', Intensive and Critical Care Nursing, 28 (2012), 6-15. 